\title{
Differential Fear Conditioning Induces Reciprocal Changes in the Sensory Responses of Lateral Amygdala Neurons to the $\mathrm{CS}^{+}$and $\mathrm{CS}^{-}$
}

\author{
Dawn R. Collins and Denis Paré ${ }^{1}$ \\ Laboratoire de Neurophysiologie, Département de Physiologie, Faculté de Médecine, Université Laval, Québec Canada G1K 7P4
}

\begin{abstract}
In classical fear conditioning, a neutral sensory stimulus (CS) acquires the ability to elicit fear responses after pairing to a noxious unconditioned stimulus (US). As amygdala lesions prevent the acquisition of fear responses and the lateral amygdaloid (LA) nucleus is the main input station of the amygdala for auditory afferents, the effect of auditory fear conditioning on the sensory responsiveness of LA neurons has been examined. Although conditioning was shown to increase CS-evoked LA responses, the specificity of the changes in responsiveness was not tested. Because conditioning might induce nonspecific increases in LA responses to auditory afferents, we re-examined this issue in conscious, head-restrained cats using a differential conditioning paradigm where only one of two tones $\left(\mathrm{CS}^{+}\right.$but not $\left.\mathrm{CS}^{-}\right)$was paired to the US. Differential conditioning increased unit and field responses to the $\mathrm{CS}^{+}$, whereas responses to the $\mathrm{CS}^{-}$ decreased. Such changes have never been observed in the amygdala except in cases where the $\mathrm{CS}^{-}$had been paired to the US before and fear responses not extinguished. This suggests that fear conditioning is not only accompanied by potentiation of amygdalopetal pathways conveying the $\mathrm{CS}^{+}$but also by the depression of sensory inputs unpaired to noxious stimuli.
\end{abstract}

The amygdaloid complex is a nucleated structure of the temporal lobe receiving sensory inputs of all modalities and projecting to functionally diverse brain structures, from the highest computational levels of the brain to hypothalamic and brainstem autonomic nuclei involved in cardiovascular control and the expression of species-specific fear responses (Hopkins and Holstege 1978; Price and Amaral 1981; Bandler 1982; Veening et al. 1984; Russchen 1986; Amaral et al. 1992).

Much evidence implicates the amygdala in fear learning and expression. For instance, stimulation of the central amygdaloid nucleus elicits increases in heart rate and blood pressure (Kaada 1972; Iwata et al. 1987). Moreover, amygdala lesions prevent the acquisition of classically conditioned fear responses (Kapp et al. 1979; Gentile et al. 1986; Iwata et al. 1986; Hitchcock and Davis 1987; LeDoux et al. 1990b; Killcross et al. 1997). These and other findings (for review, see Davis 1992; LeDoux 1995) have prompted investigators to search for the cellular correlates of fear learning in the amygdala.

As the lateral amygdaloid (LA) nucleus is the main input station of the amygdala for auditory afferents (LeDoux et al. 1990a,b; Romanski and LeDoux 1992), a few studies have examined how auditory fear conditioning affects toneevoked LA responses (Quirk et al. 1995; Rogan et al. 1997). These studies reported that fear conditioning increases auditory-evoked responses in the LA. These changes in respon-

${ }^{1}$ Corresponding author.

E-MAIL Denis.Pare@phs.Ulaval.CA; FAX (418) 656-7898. siveness were not a simple consequence of the arousal produced by the unconditioned stimulus (US) as they were not observed when the auditory conditioned stimulus (CS) and the US were presented in an unpaired manner. However, the possibility that the CS-US pairings induced nonspecific increases in LA responses to auditory afferents was not investigated.

Determining whether the changes in sensory responsiveness are specific to the conditioned tone is critical to test the idea that plastic events, taking place in the LA or one of its afferents, underlie the acquisition of fear responses. Indeed, if this is the case, the change in sensory responsiveness displayed by LA neurons should be specifically associated to the CS and not to other stimuli, much like conditioned fear responses. Thus, we re-examined this issue using a differential fear conditioning paradigm where only one of two tones $\left(\mathrm{CS}^{+}\right.$but not $\left.\mathrm{CS}^{-}\right)$was paired to a US.

\section{RESULTS}

Conscious, head-restrained cats, chronically implanted with multiple high-impedance microelectrodes in the LA, were subjected to a discriminative fear conditioning paradigm (see Materials and Methods). To assess the acquisition of conditioned fear responses, in 20 conditioning sessions, we compared changes in electromyographic (EMG) activity evoked by the $\mathrm{CS}^{+}$and the $\mathrm{CS}^{-}$before pairing (last 10 Control CS), after pairing (first 10 Extinction CS), and after extinction (last 10 Extinction CS). EMG activity was monitored by means of electrodes implanted in the posterior neck muscles.

LEARNING \& MEMORY 7:97-103 @ 2000 by Cold Spring Harbor Laboratory Press ISSN1072-0502/00 \$5.00

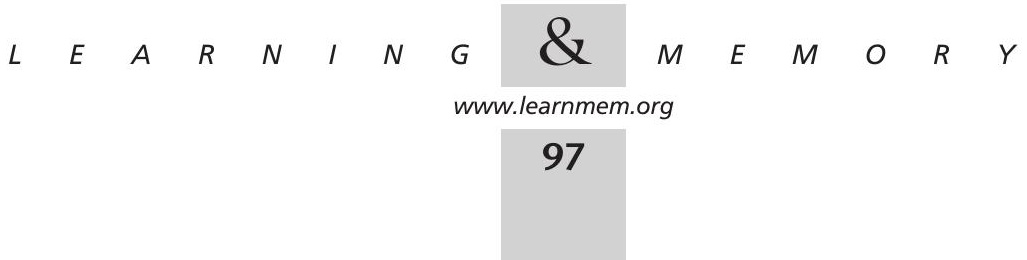




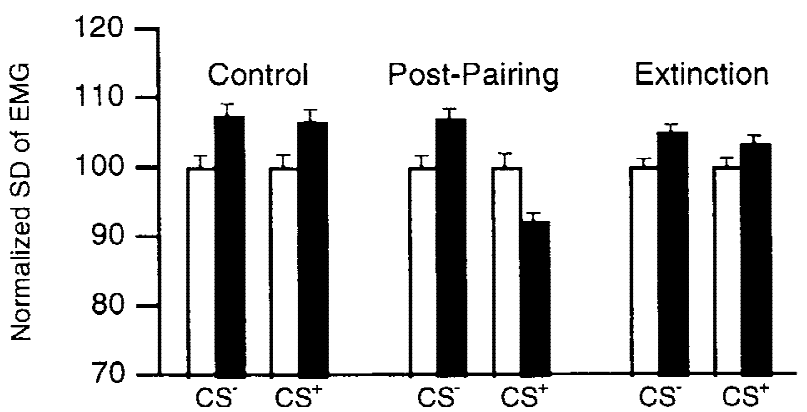

Figure 1 Conditioning produces reversible $\mathrm{CS}^{+}$-evoked decreases in EMG activity. We computed the standard deviations (s.D.) of the EMG signal (filtered $100-1000 \mathrm{~Hz}$; normalized to pretone values) during epochs of $500 \mathrm{msec}$ obtained before (open bars) and 500 msec after (solid bars) tone onsets. Bars show Control (left), Postpairing (middle), and Extinction (right) values.

Changes in EMG activity were assessed using a repeated-measures analysis of variance (ANOVA). A significant interaction was found between the stimulus $\left(\mathrm{CS}^{+}, \mathrm{CS}^{-}\right)$and the difference in EMG activity before versus during the tones $(F=21.52 ; \quad P<0.05)$. Two-tailed paired $t$-tests $\mathrm{df}=19)$ revealed that the $\mathrm{CS}^{+}$and $\mathrm{CS}^{-}$evoked an increase in EMG activity in the Control period $\left(\mathrm{CS}^{+}, 6.5 \pm 1.06 \%\right.$, $\left.t=6.13 ; \mathrm{CS}^{-}, 7.3 \pm 1.24 \%, t=7.29 ; P<0.05\right)$. In contrast, after pairing, the $\mathrm{CS}^{+}$, but not the $\mathrm{CS}^{-}$, elicited a reduction in EMG activity $(8.22 \pm 1.39 \% ; t=-5.91 ; P<0.05)$. Repeated unpaired presentations of the $\mathrm{CS}^{+}$abolished the conditioned response (Fig. 1, Extinction).

To analyze how fear conditioning influenced the auditory responsiveness of LA neurons, auditory-evoked unit discharges and field potentials were recorded simultaneously through the same LA microelectrodes. The histologically determined location of recorded sites is shown in Figure 2 (dots). In control conditions, the two tones ( 5 and $10 \mathrm{kHz}$ ) elicited a multiphasic field potential (Fig. 3, thick lines). The latency to peak of the first negative wave evoked by the two tones was not statistically different $(43.0 \pm 0.52 \mathrm{msec}$ and $42.3 \pm 0.41 \mathrm{msec}$ for 5 and $10 \mathrm{kHz}$, respectively; paired $t$-test, $\mathrm{df}=34, \quad t=1.15$, $P>0.05)$. The latency to peak of toneevoked fields is longer than that observed in rats (see, for example, Rogan and LeDoux 1995), presumably because of the larger size of cat brains.

The initial components of these auditory-evoked field potentials consisted of negative-, positive-, and negative-going waves which, in LA neurons, were associated to increasing, decreasing, and increasing firing probabilities, respectively (Fig. 3). Auditory-evoked changes in firing probabil- ity were assessed by verifying whether the first peak increase in spike counts exceeded the value required to reach statistical significance $(P<0.05)$ in a one-tailed $t$-test (average prestimulus value \pm 1.64 times the corresponding standard deviation, s.D.). In Figure 3, A, B, the peak exceeded average prestimulus values by 24.1 and 14.9 times the corresponding S.D., respectively.

The close temporal correspondence between these fluctuations in firing probability and the initial components of auditory-evoked field potentials indicate that they were not volume conducted from neighboring structures. Rather, it suggests that they reflect local extracellular currents associated with synaptic activity in the LA, as recently argued (Rogan and LeDoux 1995). In the following, we will focus on the short-latency component of this response, as much evidence suggests that it results from direct inputs originating in the auditory thalamus (Rogan and LeDoux 1995).

To measure conditioned changes in auditory responsiveness of the LA, we first compared the average amplitude of the field potentials evoked by the $\mathrm{CS}^{+}$and the $\mathrm{CS}^{-}$in the Control, Post-pairing, and Extinction phases (Fig. 4), as was done for the EMG activity (Fig. 1). To control for possible inter-sessions effects, this was performed after dividing the conditioning sessions into two groups (termed New $\mathrm{CS}^{+}$ and Repeated $\mathrm{CS}^{+}$). The first group included sessions where a different $\mathrm{CS}^{+}(5 \mathrm{kHz}$ or $10 \mathrm{kHz}$ ) had been paired to foot shocks on the previous day ( 9 sessions for a total of 20 recording sites; Fig. 4A). The second group was comprised of sessions where the same $\mathrm{CS}^{+}$had been paired on the previous day (8 sessions for a total of 15 recording sites; Fig. 4B). See Materials and Methods (Recording and Analysis) for the method used to measure the amplitude of the field potentials.

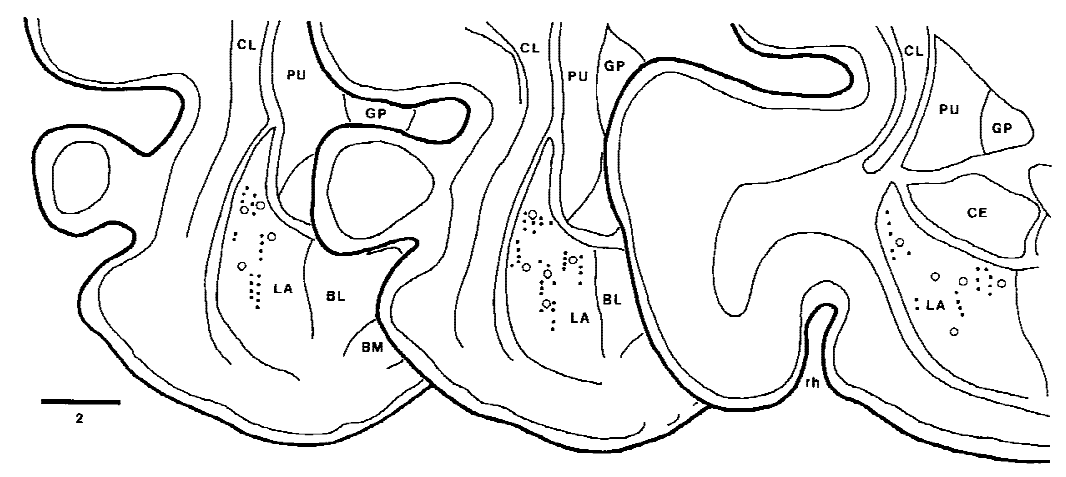

Figure 2 Location of recorded cells in the LA nucleus. Scheme of three coronal sections arranged from rostral (left) to caudal (right). Dots indicate the location of cells recorded in conditioning experiments. (O) Cells recorded in experiments where tones were presented without US to determine whether their tone responses habituated. The location of recorded cells was determined from thionin-stained coronal sections, by combining micrometric readings with the placement of electrolytic lesions (see Materials and Methods for details). (BL) Basolateral nucleus of the amygdala; (BM) basomedial nucleus of the amygdala; (CE) central nucleus of the amygdala; (CL) claustrum; (GP) globus pallidus; (LA) lateral nucleus of the amygdala; (PU) putamen; (rh) rhinal sulcus. Bar, $2 \mathrm{~mm}$.

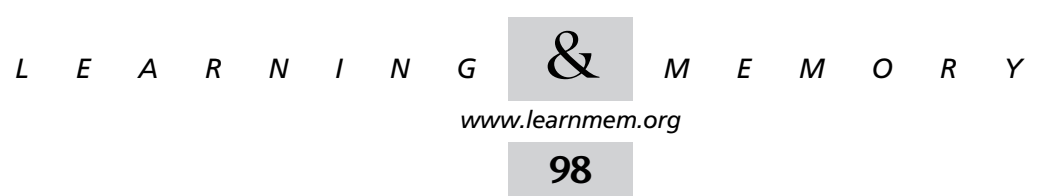



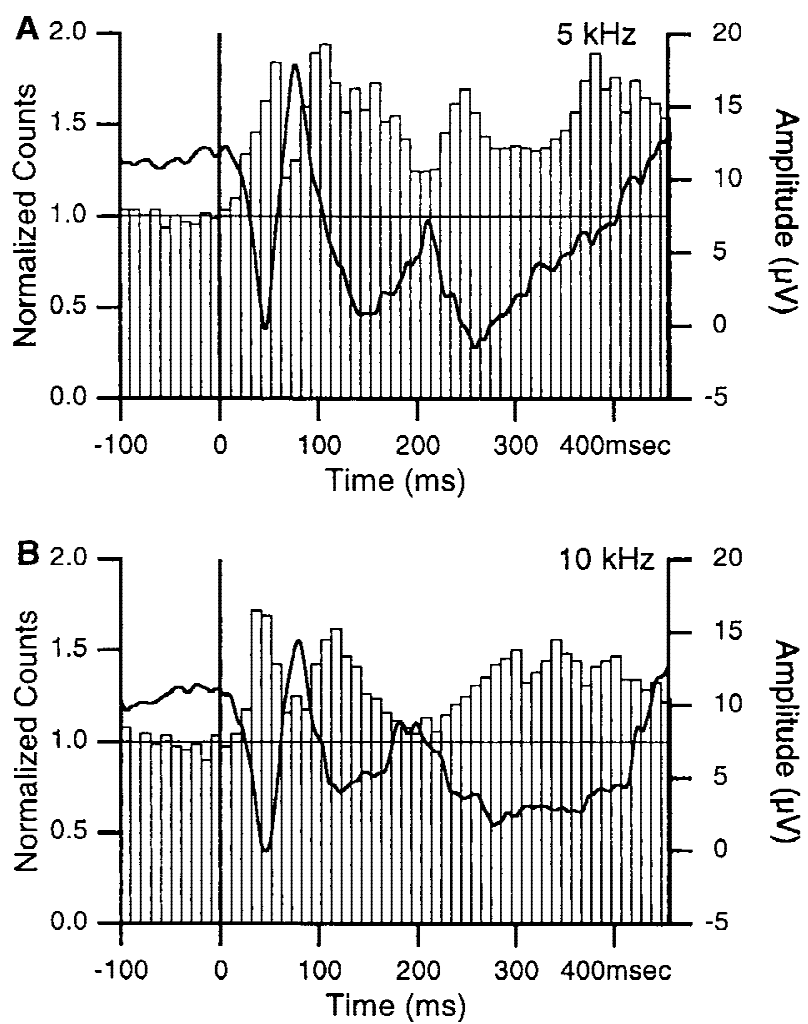

Figure 3 Auditory-evoked field potentials and unit activity in the LA. Responses to 1 -sec tones of $5(A)$ and $10(B) \mathrm{kHz}$. Vertical lines indicate tone onsets. Focal waves were digitally filtered $(3-300 \mathrm{~Hz}$, thick lines). Each tone was presented 20 times and the responses of 35 LA sites averaged. Superimposed on the focal waves are peristimulus histograms showing the summed activity of 72 LA neurons. Bins of $10 \mathrm{msec}$.

Figure 4 depicts the average field potentials elicited by the $\mathrm{CS}^{+}$and $\mathrm{CS}^{-}$in the LA for the two groups of sessions, in the three phases. See the legend of Figure 4 for the amplitude of the field potentials. Changes in field potential amplitude were assessed using a repeated-measures ANOVA. A significant interaction was found between the stimulus $\left(\mathrm{CS}^{+}, \mathrm{CS}^{-}\right)$and experimental phase (Control, Post-pairing, Extinction; $\mathrm{F}=16.75 ; P<0.05)$ but not with the session order $\left(\mathrm{New} \mathrm{CS}^{+}\right.$, Repeated $\left.\mathrm{CS}^{+} ; \mathrm{F}=0.38\right)$. The effect of the stimulus, experimental phase and session order variables did not reach significance $(F=0.26,1.59,0.07$, respectively).

Two-tailed paired $t$-tests revealed that, irrespective of the order in which the $\mathrm{CS}^{+}$was presented on consecutive days, the differential conditioning paradigm significantly increased focal LA responses to the $\mathrm{CS}^{+}\left(\mathrm{New} \mathrm{CS}^{+}\right.$, by $111 \pm 49.7 \%, t=2.28$; Repeated $\mathrm{CS}^{+}, 64 \pm 14.2 \%, t=3.63$; $P<0.05)$ and decreased those to the $\mathrm{CS}^{-}$(New $\mathrm{CS}^{-}$, by $41 \pm 30.3 \%, t=-3.22$; Repeated $\mathrm{CS}^{-}, 61 \pm 18.7 \%, t=-3.16$; $P<0.05)$. Auditory-evoked field potentials returned toward control values following extinction. However, $\mathrm{CS}^{-}$-evoked responses remained significantly lower than control ones $(t=-3.19$ and -2.31 for sessions with new and repeated $\mathrm{CS}^{+}$, respectively).

Differences in the amplitude of field responses evoked by the $\mathrm{CS}^{+}$and $\mathrm{CS}^{-}$in the Control phase did not reach significance for the New $\mathrm{CS}^{+}$group of sessions ( $\mathrm{df}=19$, $t=1.21, P>0.05$ ), but did for the Repeated $\mathrm{CS}^{+}$group (df $=14, t=3.002, P<0.05$ ). This difference results from the fact that $10 \mathrm{kHz}$ tones tended to evoke smaller field responses (see Fig. 3B) and that, by chance, more $10 \mathrm{kHz}$ tones happened to be used as the $\mathrm{CS}^{+}$.

We then turned our attention to the changes in auditory-evoked unit activity induced by fear conditioning. One obstacle in carrying out such analyses is that most LA neurons fire at low rates (Paré and Gaudreau 1996; Collins and Paré 1999). Thus, to maximize spike counts, and because the above analysis revealed that the session order did not affect the directions of the changes, all LA units $(n=72)$ were pooled together (Fig. 5).

Modifications in auditory-evoked firing were analyzed as follows. For each condition, the difference between the two bins coinciding with the peak of the first negative focal wave and the prestimulus bins was computed, resulting in six arrays of 20 values. Using a repeated-measures ANOVA, a significant interaction was found between the stimulus and experimental phase variables $(F=251.03 ; P<0.05)$. A significant effect of the stimulus and experimental phase variables was also found $(F=412.57$ and 152.79 , respectively).

Consistent with the changes in auditory-evoked field potentials, two-tailed paired $t$-tests $(\mathrm{df}=19)$ revealed that although responsiveness to the two stimuli was not different in control conditions $(t=2.003)$, pairing increased $(P<0.05)$ responses to the $\mathrm{CS}^{+}$(by $54 \pm 2.7 \%, t=20.09$ ) and decreased $(P<0.05)$ those to the $\mathrm{CS}^{-}$(by $33 \pm 2.1 \%$, $t=10.85)$. After extinction, responses returned toward control values, but remained significantly different $\left(\mathrm{CS}^{+}, t=5.3\right.$; $\mathrm{CS}^{-}, t=7.3$ ).

To determine whether the depression of $\mathrm{CS}^{-}$-evoked activity reflected habituation of responses, we analyzed the auditory responsiveness of 14 additional LA cells recorded in the course of previous extracellular studies on the activity of amygdala neurons (Collins and Paré 1999; D. Paré, unpubl.). These cells (empty circles in Fig. 2) were selected because they were clearly tone responsive and the animals had never been presented the tones $(3-10 \mathrm{kHz})$ prior to the recordings. The averaged unit and field response to tone presentations 1-10 (Fig. 6A) and 31-40 (Fig. 6B) was analyzed. Note that in contrast with the previous experiments, tones 21-30 were not paired to foot shocks.

The amplitude of field responses averaged 16.4 \pm 3.3 $\mu \mathrm{V}$ and $16.2 \pm 2.7 \mu \mathrm{V}$ for tone presentations $1-10$ (Fig. 6A) and 31-40 (Fig. 6B), respectively. The difference was not statistically significant ( $\mathrm{df}=13, t=0.07, P>0.05)$. To determine whether the auditory responsiveness of the cells

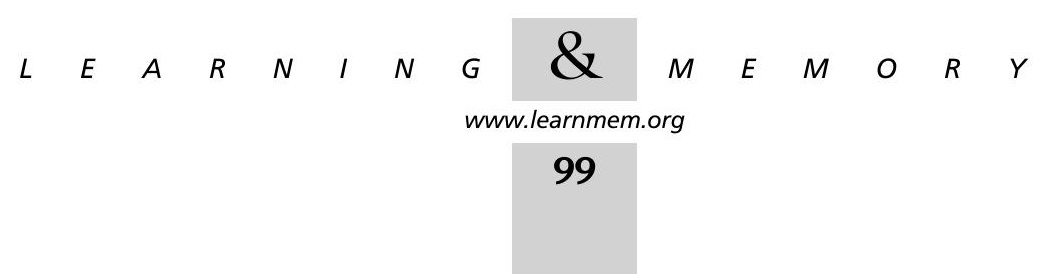


A New $\mathrm{CS}^{+}$

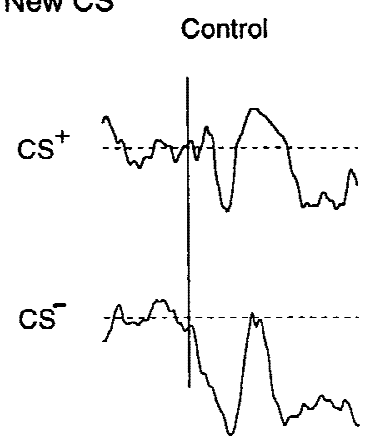

B Repeated $\mathrm{CS}^{+}$

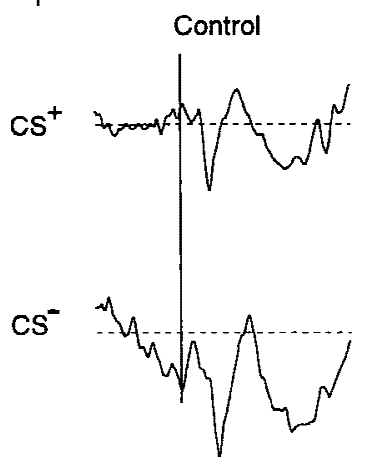

Post-Pairing

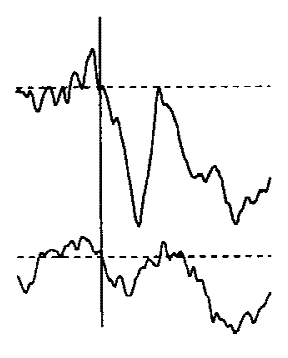

Extinction
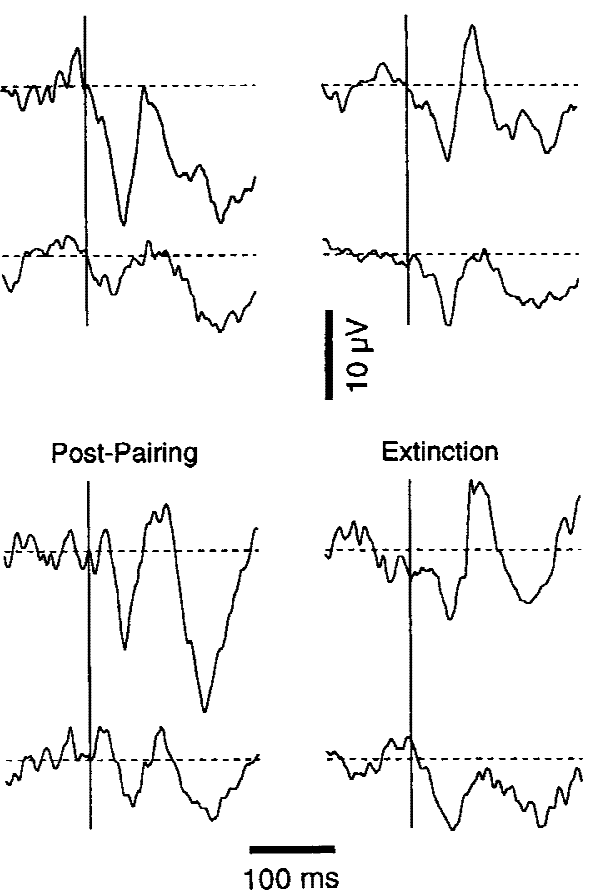

Figure 4 Conditioning causes opposite changes in focal LA responses to the $\mathrm{CS}^{+}$and $\mathrm{CS}^{-}$. Average auditory-evoked responses in sessions where a different $(A)$ or the same $(B)$ $\mathrm{CS}^{+}$was used in the previous session. Broken lines indicate average voltage values before the tone onsets. The average amplitude of the field potentials (in $\mu \mathrm{V}$ ) in $A$ are, for the $\mathrm{CS}^{+}$: Control, $7.5 \pm 2.9$; Post-Pairing, $15.8 \pm 3.79$; Extinction, $8.6 \pm 2.33$. For the $\mathrm{CS}^{-}$, Control, $13.3 \pm 3.19$; Post-Pairing, $4.8 \pm 2.05$; Extinction, $7.9 \pm 3.09$. In $B$, for the $\mathrm{CS}^{+}$, Control, $7.4 \pm 2.11$; Post-Pairing, $12.1 \pm 3.4$; Extinction, $8.5 \pm 2.26$. For the $\mathrm{CS}^{-}$, they are Control, $13.9 \pm 2.48$; Post-Pairing, $5.4 \pm 1.66$; Extinction, $8.2 \pm 2.17$. Vertical bar, $10 \mu \mathrm{V}$; horizontal bar $100 \mathrm{msec}$.

changed from tones 1-10 to tones 31-40, the difference between the two bins coinciding with the peak of the first negative focal wave and the prestimulus bins was computed, resulting in two arrays of 20 values. However, the difference did not reach significance ( $\mathrm{df}=19, t=0.058, P>0.05)$.

\section{DISCUSSION}

\section{Nature of the Conditioned EMG Responses}

In this study, conditioned fear reactions were assessed by comparing the changes in EMG activity evoked by the $\mathrm{CS}^{+}$ and $\mathrm{CS}^{-}$before and after conditioning. In the control period, the $\mathrm{CS}^{+}$and $\mathrm{CS}^{-}$evoked an increase in EMG activity of the posterior neck muscles whereas after pairing, the $\mathrm{CS}^{+}$, but not the $\mathrm{CS}^{-}$, elicited a reduction in EMG activity.

This result might seem surprising as, following fear conditioning, freely moving rats were reported to exhibit increased CS-evoked EMG responses associated with freezing (Hennevin et al. 1998). We speculate that our counterintuitive finding is a consequence of the head restraint imposed on the animals. The animals quickly learned that

release from the head restraint involves downward head movements. Presumably, the opposite result would have been obtained had we recorded from muscles assisting these movements.

Nevertheless, irrespective of the underlying mechanisms, the specificity of the conditioned EMG response suggests that it resulted from the differential pairing of the $\mathrm{CS}^{+}$to the shocks, not from a nonspecific arousal produced by the shocks or the auditory stimuli.

\section{Modifications in Auditory Responsiveness}

Previous studies examining the effect of fear conditioning on the auditory responsiveness of LA neurons (Quirk et al. 1995; Rogan et al. 1997; Hennevin et al. 1998) can be criticized for two reasons (Malenka and Nicoll 1997). First, the increase in auditoryevoked LA responses caused by fear conditioning was not shown to be specific to the conditioned tone. Second, the possibility that conditioned increases in responsiveness reflected alterations in auditory relays located upstream from the LA could not be excluded.

With regards to the first criticism, our results demonstrate that fear conditioning does not provoke a nonspecific increase in auditory responsiveness. Rather, fear learning is accompanied by a potentiation of responses to the $\mathrm{CS}^{+}$and a depression of those to the $\mathrm{CS}^{-}$. In fact, our study is the first to show that the changes in auditory responsiveness produced by fear conditioning in the LA are frequency specific.

Several studies using discriminative fear conditioning have reported specific increases in the responsiveness of other amygdala neurons to the $\mathrm{CS}^{+}$(see, for example, Pascoe and Kapp 1985; Maren et al. 1991; McEchron et al. 1995). However, in contrast with the present findings, decreases in responsiveness to the $\mathrm{CS}^{-}$were not observed in the amygdala except in cases where the $\mathrm{CS}^{-}$had been paired previously to the US and the fear responses not extinguished, an approach known as reversal. This is in contrast with the paradigm used here, where the two CS were presented 60 times each to extinguish fear responses prior to the next conditioning session.

Several factors suggest that the decreased LA responses to the $\mathrm{CS}^{-}$induced by fear conditioning do not reflect a simple habituation. First, previous work has shown that explicitly unpaired presentations of the US and one auditory CS do not provoke significant decreases in evoked re-

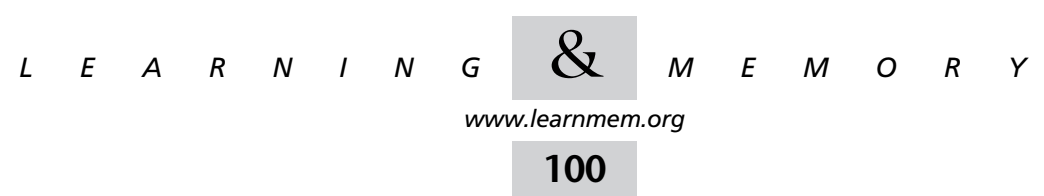



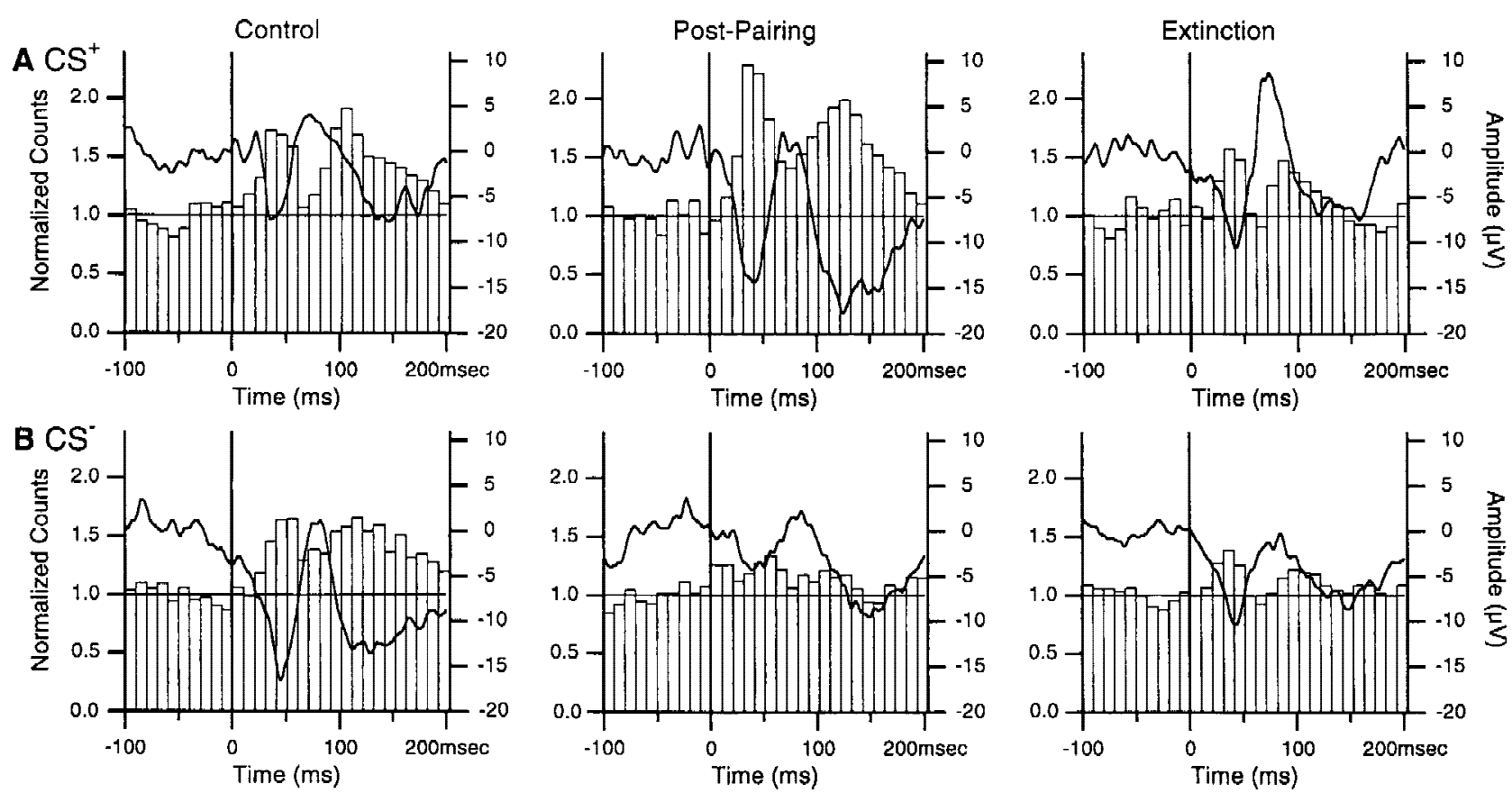

Figure 5 Conditioning causes inverse changes in unit responses to the $\mathrm{CS}^{+}(A)$ and $\mathrm{CS}^{-}(B)$ in the LA. The responses of 72 neurons were summed and normalized to the average prestimulus bin height and superimposed on average focal waves (thick lines). Using the criteria of Fig. 3, short-latency increases in firing probability were significant $(P<0.05)$ in all conditions.

sponses (Rogan et al. 1997). Second, in our study, $\mathrm{CS}^{-}$evoked responses returned toward control values following repeated unpaired presentation of the two tones. Last, repeated presentations of the tones without the noxious stimuli did not depress significantly tone-evoked unit and field responses in the LA. These considerations suggest that the differential association of the two tones to the US is essential for decreases in $\mathrm{CS}^{-}$-evoked responses to be observed.

Regarding the second criticism, previous studies examining the effects of fear conditioning on the auditory responsiveness of thalamic and cortical auditory neurons (Oleson et al. 1975; Disterhoft and Stuart 1976; Ryugo and Weinberger 1978; Bakin and Weinberger 1990; Edeline and Weinberger 1992) reported that conditioning increased responses to the $\mathrm{CS}^{+}$. Thus, potentiation of $\mathrm{CS}^{+}$-evoked LA responses observed in this and previous studies (Quirk et al. 1995; Rogan et al. 1997) could reflect, in part or totality, alterations in auditory relays located upstream from the LA. However, the reportedly late development of conditioned responses in the auditory cortex compared to the LA (Quirk et al. 1997) suggests that thalamic inputs play a predominant role in this respect.

It is unclear whether the pronounced depression of $\mathrm{CS}^{-}$-evoked LA responses observed here can be explained by changes occurring at the thalamic or cortical levels. In studies comparable to ours, responses to unpaired tones were described as unchanged (medial geniculate, Ryugo and Weinberger 1978), slightly increased (auditory cortex, Oleson et al. 1975), or decreased by an average of 12-16\% (auditory cortex, Bakin and Weinberger 1990; medial geniculate, Edeline and Weinberger 1992). The reduction observed in the latter studies represents roughly half the effect observed here.

Although this difference suggests that the decreased responsiveness of LA neurons to the $\mathrm{CS}^{-}$cannot be ascribed solely to changes in thalamic or cortical afferents, this point awaits confirmation using simultaneous recordings in these various sites. If true, this finding would constitute strong evidence that the amygdala does more than relay sensory inputs to brain structures mediating fear responses, a much debated issue (Cahill et al. 1999; Fanselow and LeDoux 1999).

\section{MATERIALS AND METHODS}

\section{Surgery}

Experiments were conducted in four adult cats in agreement with the guidelines of the Canadian Council on Animal Care. Research protocols were approved by the local ethics committee of University Laval. We chose this species because the large size of cat brains facilitate the placement of multiple microelectrodes in different nuclei of the amygdala.

The anesthesia was induced with ketamine $(15 \mathrm{mg} / \mathrm{kg}$, i.m.) and atropine sulfate $(0.05 \mathrm{mg} / \mathrm{kg}, \mathrm{i} . \mathrm{m}$.) was administered to prevent secretions. Then, sodium pentobarbital was injected gradually (Somnotol, $15 \mathrm{mg} / \mathrm{kg}$, i.v.). The bone overlying the amygdaloid complex was removed on one side and the dura mater removed. Then, an array of 21 tungsten microelectrodes (3 rows of 7 elec-

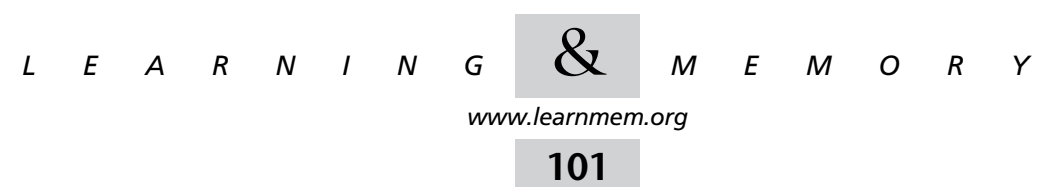




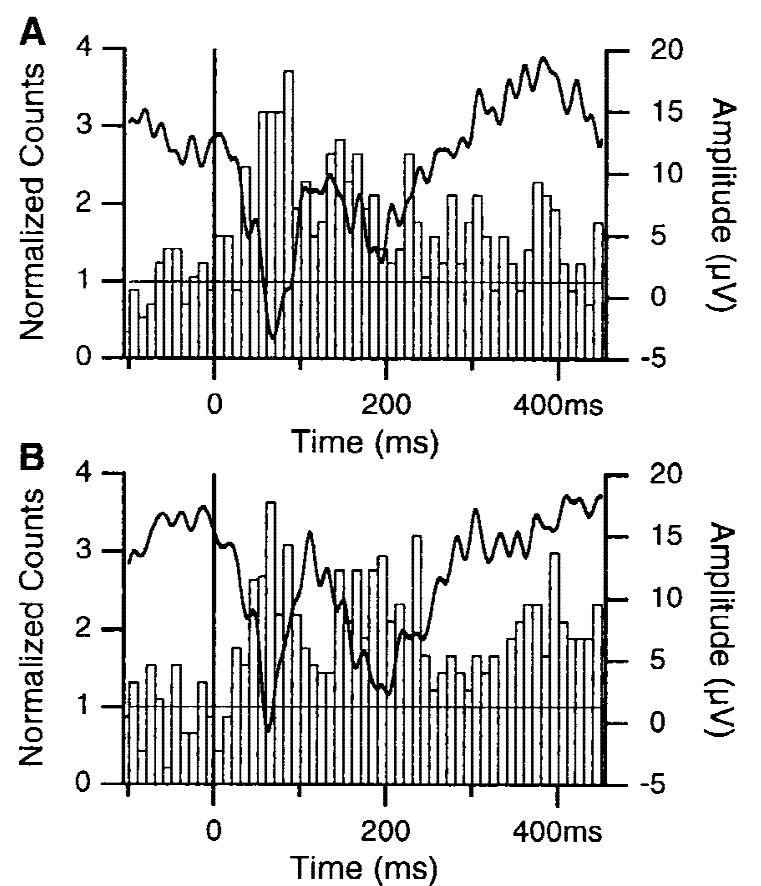

Figure 6 Effect of multiple presentations of the same tones on the responsiveness of LA cells. Averaged field (thick lines, right axis) and unit responses (histograms, left axis; $n=14$ ) to presentations $1-10(A)$ and $31-40(B)$ of the same tones $(3-10 \mathrm{kHz})$. Bins of ten msec. When the cells were recorded, the animals had never been presented these tones before and no foot shock had been administered in conjunction to auditory stimuli. Note that the spike counts were normalized to the average pretone activity.

trodes) was lowered until the electrodes reached the dorsal aspect of the amygdala. These electrodes (FHC, Brunswick, ME) had a maximal outer diameter of $80 \mu \mathrm{m}$ and an impedance of 2-6 $\mathrm{m}$ at $1 \mathrm{KHz}$. To construct the array, small holes were drilled in a circular delrin block and the electrodes inserted into them. The delrin block was inserted in a tightly fitting sleeve that was cemented to the bone. During the recording sessions, the electrodes could be lowered by means of a screw pushing on the delrin block. To monitor the muscle tone, two Teflon-insulated wires were inserted in the posterior neck muscles. Finally, four screws were cemented to the skull to fix the cat's head in a stereotaxic position without pain or pressure. Recording sessions began six days later. Bicillin (i.m. daily for 3 days) and buprenorphine $(0.03 \mathrm{mg} / \mathrm{kg}$, i.m. every $12 \mathrm{hr}$ for 24 hr) were administered postoperatively. Recording sessions began six to eight days after the surgery. In between experimental sessions, the animals slept, ate, and drank ad libitum. At the end of the experiments, the animals were deeply anesthetized $(40 \mathrm{mg} / \mathrm{kg})$ and selected recording sites were marked with electrolytic lesions $(0.5$ $\mathrm{mA}$ for $5 \mathrm{sec}$ ). Then, they were perfused with saline followed by a fixative. The brains were sectioned at $80 \mu \mathrm{m}$ and stained with thionin. The microelectrode tracks were reconstructed by combining micrometer readings with the histological controls, as shown in Collins and Paré (1999).

\section{Recording and Analysis}

The activity of LA neurons was observed on a digital oscilloscope, printed on a chart recorder, digitized, and stored on tape. Analyses were performed off-line with the software IGOR (Wavemetrics,
Oregon) and homemade software running on Macintosh microcomputers. Field potentials and unit activity were recorded simultaneously with the same electrodes and isolated off-line using digital filtering (action potentials, $0.3-10 \mathrm{kHz}$; field potentials, 3-300 $\mathrm{Hz}$ ). The average amplitude of tone-evoked field potentials was measured by subtracting the voltage $42.7 \mathrm{msec}$ after the tone onset from the average voltage value (broken lines in Fig. 4) of the 100 msec preceding the tone onset. The interval of $42.7 \mathrm{msec}$ corresponds to the average latency to peak of the field potentials evoked by the 5 and $10 \mathrm{kHz}$ tones (see Results). Spikes were detected with a window discriminator after digital filtering of the data. Peristimulus histograms were smoothed with a moving average of 3 .

The LA contains two main cell types (see McDonald 1992). Most cells (85\%) are spiny glutamatergic projection neurons and a minority of cells are aspiny local-circuit neurons immunopositive for $\gamma$-aminobutyric acid (GABA; McDonald 1985; McDonald and Augustine 1993; Paré and Smith 1993). Thus, our sample of LA neurons should be mainly comprised of projection cells. Nevertheless, to ensure that we studied an homogeneous population of neurons, we attempted to further restrict our analyses to projection cells. We distinguished projection cells from interneurons on the basis of criteria obtained in a previous electrophysiological investigation of LA neurons in behaving cats (Paré and Gaudreau 1996). In this study, all LA neurons that could be backfired from known projection fields of the LA fired spontaneously at low rates (generally $<1 \mathrm{~Hz}$ ) whereas none of the cells with high spontaneous firing rates $(>10 \mathrm{~Hz})$ could be antidromically invaded. Consequently, they were presumed to be local-circuit cells. This idea is supported by the results of intracellular studies where the physiological and morphological properties of LA neurons were correlated (Paré et al. 1995; Lang and Paré 1998), revealing that aspiny neurons of the LA can sustain high firing rates for prolonged periods of time (Paré et al. 1995; Lang and Paré 1998). Thus, in the present study, all cells of the LA with high spontaneous firing rates $(>5 \mathrm{~Hz})$ were excluded from the analyses.

\section{Conditioning}

Auditory stimuli consisted of 1 -sec tones of 5 or $10 \mathrm{kHz}$ at $60 \mathrm{db}$. The US were electrical shocks $(0.5 \mathrm{sec}, 1.5 \mathrm{~mA})$ delivered to the front paws by means of surface electrodes $0.5 \mathrm{sec}$ after the $\mathrm{CS}^{+}$ onset. Inter-tone intervals ranged between $2 \mathrm{sec}$ and $5 \mathrm{~min}$. Each recording session the electrode array was lowered 80-200 $\mu \mathrm{m}$ and the electrodes scanned for units with a signal to noise ratio $\geq 3$. Thirty minutes later, the cats were presented two different tones $(5$ and $10 \mathrm{kHz}), 20$ times, in a random order. Subsequently, one of the two tones $\left(\mathrm{CS}^{+}\right)$was presented 10 times, paired to a foot shock, with an equal number of randomly interspersed $\mathrm{CS}^{-}$presentations. To extinguish conditioned fear responses, 60 unpaired presentations of the two tones followed. Hereafter, these three phases of the conditioning paradigm will be referred to as the Control, Pairing, and Extinction phases, respectively. On subsequent days, the same protocol was carried out with the proviso that the $\mathrm{CS}^{+}$could remain the same or change, randomly. Fewer than six conditioning sessions were performed in each cat.

\section{ACKNOWLEDGMENTS}

This work was supported by the Canadian Medical Research Council. We would like to thank Drs. M. Davis, É. Audinat, S. Charpak, and E.J. Lang for useful comments on an earlier version of this manuscript.

The publication costs of this article were defrayed in part by payment of page charges. This article must therefore be hereby

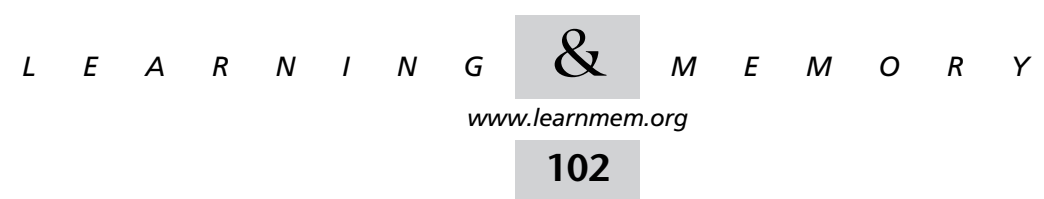


marked "advertisement" in accordance with 18 USC section 1734 solely to indicate this fact.

\section{REFERENCES}

Amaral, D.G., J.L. Price, A. Pitkänen, and S.T. Carmichael. 1992. Anatomical organization of the primate amygdaloid complex. In The amygdala: Neurobiological aspects of emotion, memory, and mental dysfunction (ed. J.P. Aggleton), pp. 1-66. Wiley-Liss, New York, NY.

Bakin, J.S. and N.M. Weinberger. 1990. Classical conditioning induces CS-specific receptive field plasticity in the auditory cortex of the guinea pig. Brain Res. 536: 271-286.

Bandler, R. 1982. Induction of "rage" following microinjections of glutamate into midbrain but not hypothalamus of cats. Neurosci. Lett. 5: 183-188.

Cahill, L., N.M. Weinberger, B. Roozendaal, and J.L. McGaugh. 1999. Is the amygdala a locus of "conditioned fear"? Some questions and caveats. Neuron 23: 227-228.

Collins, D.R. and D. Paré. 1999. Reciprocal changes in the firing probability of lateral and central medial amygdala neurons. J. Neurosci. 19: 836-844.

Davis, M. 1992. The role of the amygdala in fear and anxiety. Annu. Rev. Neurosci. 15: 353-375.

Disterhoft, J.F. and D.K. Stuart. 1976. Trial sequence of changed unit activity in auditory system of alert rat during conditioned response acquisition and extinction. J. Neurophysiol. 39: 266-281.

Edeline, J.M. and N.M. Weinberger. 1992. Associative retuning in the thalamic source of input to the amygdala and auditory cortex: Receptive field plasticity in the medial division of the medial geniculate body. Behav. Neurosci. 106: 81-105.

Fanselow, M.S. and J.E. LeDoux. 1999. Why we think plasticity underlying Pavlovian fear conditioning occurs in the basolateral amygdala. Neuron 23: 229-232.

Gentile, C.G., T.W. Jarrell, A.H. Teich, P.M. McCabe, and N. Schneiderman. 1986. The role of amygdaloid central nucleus in differential Pavlovian conditioning of bradycardia in rabbits. Behav. Brain Res. 20: 263-276.

Hennevin, E., C. Maho, and B. Hars. 1998. Neuronal plasticity induced by fear conditioning is expressed during paradoxical sleep: Evidence from simultaneous recordings in the lateral amygdala and the medial geniculate in rats. Behav. Neurosci. 112: 839-862.

Hitchcock, J.M. and M. Davis. 1987. Fear-potentiated startle using an auditory conditioned stimulus: effect of lesions of the amygdala. Physiol. Behav. 39: 403-408.

Hopkins, D.A. and G. Holstege. 1978. Amygdaloid projections to the mesencephalon, pons and medulla oblongata in the cat. Exp. Brain Res. 32: 529-547.

Iwata, J., J.E. LeDoux, M.P. Meeley, S. Arneric, and D.J. Reis. 1986. Intrinsic neurons in the amygdaloid field projected to by the medial geniculate body mediate emotional responses conditioned to acoustic stimuli. Brain Res. 383: 195-214.

Iwata, J., K. Chida, and J.E. LeDoux. 1987. Cardiovascular responses by stimulation of neurons in the central nucleus of the amygdala in awake but not anesthetized rats resemble conditioned emotional responses. Brain Res. 418: 183-188.

Kaada, B.R. 1972. Stimulation and regional ablation of the amygdaloid complex with reference to functional representations. In: The neurobiology of the amygdala (ed. B.E. Elefther), pp. 205-281. Plenum, New York, NY.

Kapp, B.S., R.C. Frysinger, M. Gallagher, and J.R. Haselton. 1979. Amygdala central nucleus lesions: Effects on heart rate conditioning in the rabbit. Physiol. Behav. 23: 1109-1117.

Killcross, S., T.W. Robbins, and B.J. Everitt. 1997. Different types of fear-conditioned behaviour mediated by separate nuclei within amygdala. Nature 388: 377-380.

Lang, E.J. and D. Paré. 1998. Synaptic responsiveness of interneurons of the cat lateral amygdaloid nucleus. Neuroscience 83: 877-889.

LeDoux, J.E. 1995. Emotion: Clues from the brain. Annu. Rev. Psychol. 46: $209-235$

LeDoux, J.E., P. Cicchetti, A. Xagoraris, and L.M. Romanski. 1990a. The lateral amygdaloid nucleus: sensory interface of the amygdala in fear conditioning. J. Neurosci. 10: 1062-1069.

LeDoux, J.E., C. Farb, and D.A. Ruggiero. 1990b. Topographic organization of neurons in the acoustic thalamus that project to the amygdala. $J$. Neurosci. 10: 1043-1054.

Malenka, R.C. and R.A. Nicoll. 1997. Learning and memory-Never fear, LTP is hear. Nature 390: 552-553.

Maren, S., A. Poremba, and M. Gabriel. 1991. Basolateral amygdaloid multi-unit neuronal correlates of discriminative avoidance learning in rabbits. Brain Res. 549: 311-316.

McDonald, A.J. 1985. Immunohistochemical identification of gamma-aminobutyric acid-containing neurons in the rat basolateral amygdala. Neurosci. Lett. 53: 203-207.

- 1992. Cell types and intrinsic connections of the amygdala. In The amygdala: Neurobiological aspects of emotion, memory, and mental dysfunction (ed. J.P. Aggleton), pp. 67-96. Wiley-Liss, New York, NY.

McDonald, A.J. and J.R. Augustine. 1993. Localization of GABA-like immunoreactivity in the monkey amygdala. Neuroscience 52: 281-294.

McEchron, M.D., P.M. McCabe, E.J. Green, M.M. Llabre, and N. Schneiderman. 1995. Simultaneous single unit recordings in the medial nucleus of the medial geniculate nucleus and amygdaloid central nucleus throughout habituation, acquisition, and extinction of the rabbit's classically conditioned heart rate. Brain Res. 682: 157-166.

Oleson, T.D., J.H. Ashe, and N.M. Weinberger. 1975. Modification of auditory and somatosensory system activity during pupillary conditioning in the paralyzed cat. J. Neurophysiol. 38: 1114-1139.

Paré, D. and Y. Smith. 1993. Distribution of GABA immunoreactivity in the amygdaloid complex of the cat. Neuroscience 57: 1061-1076.

Paré, D. and H. Gaudreau. 1996. Projection cells and interneurons of the lateral and basolateral amygdala: Distinct firing patterns and differential relation to theta and delta rhythms in conscious cats. J. Neurosci. 16: 3334-3350.

Paré, D., H.C. Pape, and J.M. Dong. 1995. Bursting and oscillating neurons of the cat basolateral amygdaloid complex in vivo: Electrophysiological properties and morphological features. J. Neurophysiol. 74: 1179-1191.

Pascoe, J.P. and B.S. Kapp. 1985. Electrophysiological characteristics of amygdaloid central nucleus neurons during Pavlovian fear conditioning in the rabbit. Behav. Brain Res. 16: 117-133.

Price, J.L. and D.G. Amaral. 1981. An autoradiographic study of the projections of the central nucleus of the monkey amygdala. $J$. Neurosci. 1: 1242-1259.

Quirk, G.J., J.C. Repa, and J.E. LeDoux. 1995. Fear conditioning enhances short-latency auditory responses of lateral amygdala neurons: Parallel recordings in the freely behaving rat. Neuron 15: 1029-1039.

Quirk, G.J., J.L. Armony, and J.E. LeDoux. 1997. Fear conditioning enhances different temporal components of tone-evoked spike trains in auditory cortex and lateral amygdala. Neuron 19: 613-624.

Rogan, M.T. and J.E. LeDoux. 1995. LTP is accompanied by commensurate enhancement of auditory-evoked responses in a fear conditioning circuit. Neuron 15: 127-136.

Rogan, M.T., U.V. Stäubli, and J.E. LeDoux. 1997. Fear conditioning induces associative long-term potentiation in the amygdala. Nature 390: 604-607.

Romanski, L.M. and J.E. LeDoux. 1992. Equipotentiality of thalamo-amygdala and thalamo-cortico-amygdala circuits in auditory fear conditioning. J. Neurosci. 12: 4501-4509.

Russchen, F.T. 1986. Cortical and subcortical afferents of the amygdaloid complex. In Excitatory amino acids and epilepsy (ed. Schwarz, R. and Y. Ben-Ari.), pp. 35-52. Plenum, New York, NY.

Ryugo, D.K. and N.M. Weinberger. 1978. Differential plasticity of morphologically distinct neuron populations in the medial geniculate body of the cat during classical conditioning. Behav. Biol. 22: 275-301.

Veening, J.G., L.W. Swanson, and P.E. Sawchenko. 1984. The organization of projections from the central nucleus of the amygdala to brainstem sites involved in central autonomic regulation: A combined retrograde transport-immunohistochemical study. Brain Res. 303: 337-357.

Received November 29, 1999; accepted in revised form February 7, 2000 .

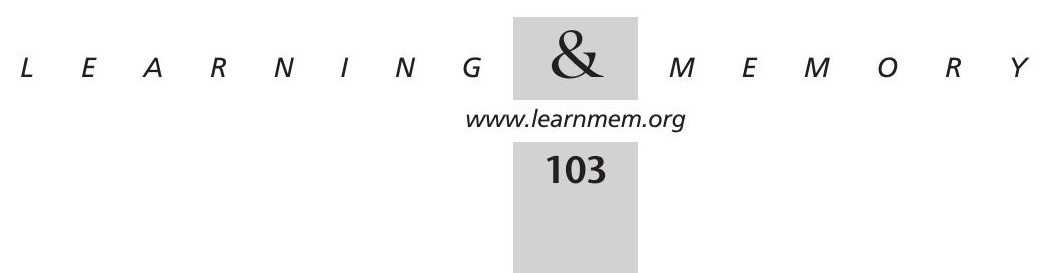




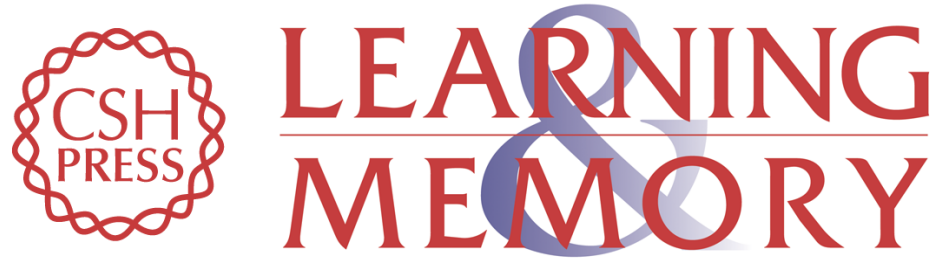

\section{Differential Fear Conditioning Induces Reciprocal Changes in the Sensory Responses of Lateral Amygdala Neurons to the CS ${ }^{+}$and $\mathrm{CS}^{-}$}

Dawn R. Collins and Denis Paré

Learn. Mem. 2000, 7:

Access the most recent version at doi:10.1101//m.7.2.97

References This article cites 37 articles, 6 of which can be accessed free at: http://learnmem.cshlp.org/content/7/2/97.full.html\#ref-list-1

License

Email Alerting

Receive free email alerts when new articles cite this article - sign up in the box at the Service top right corner of the article or click here. 